Revista Iberoamericana, Vol. LXXI, Núm. 213, Octubre-Diciembre 2005, 1179-1189

\title{
LOS HÉROES EN LA ESTRATEGIA LITERARIA DE SOBRE HÉROES Y TUMBAS Y ABADDÓN EL EXTERMINADOR DE ERNESTO SÁBATO
}

POR

Maria Grazia Spiga Bannura

Université de Paris XII

Le théâtre du héros, c’est le livre.

Julia Kristeva

Fuerza referencial y actividad autorreflexiva estructuran numerosas fórmulas textuales al entremezclarse. A menudo la ficción entrevera poder de reproducción de una realidad no verbal y discurso estético, recalcando la importancia tanto de la denotación como de lo formal. Italo Calvino ha evocado las sutiles posibilidades de asociación entre "mundo no escrito" y "mundo escrito" (Daros 161) en el espacio de la página. Por su parte, mediante la relectura de la Poética de Aristóteles, Paul Ricoeur ha relacionado la mímesis con el conocimiento del mundo al caracterizarla como una "imitación creadora" (Compagnon 136-7) que da forma a la experiencia. Si el escritor y teórico italiano define la literatura como un "entrelazamiento de distintos niveles de realidad" (Calvino 85), el filósofo francés estudia las diferentes modalidades del "entrecruzamiento entre historia y ficción” (Temps 330). Más recientemente, en La mémoire, l'histoire, l'oubli, Paul Ricoeur ha hecho énfasis en la imbricación entre historia y memoria que logra recuperar sucesos incluso olvidados. Ambas utilizan, reproducen y mezclan acontecimientos que recuerdan y reelaboran. Si la historia se nutre esencialmente de pruebas que justifican la evocación del pasado, la ficción no vacila en crear las que se necesitan para transcribir lo que se perdió. De manera paradójica, la invención desemboca en una reconstitución auténtica gracias al entrelazamiento de unas informaciones disponibles y otras fabricadas puesto que faltan. Así, sacando provecho de su libertad, el texto literario reconstruye e ilumina a la vez el mundo referencial consiguiendo recuperar lo descartado, lo perdido en la transmisión de la memoria, a partir de la búsqueda de un sentido más allá de la ausencia.

Hace unas décadas, las producciones de Ernesto Sábato entretejían verdad histórica y fidelidad mnésica en el entramado narrativo para restituir trayectorias épicas que los libros de historia solo evocan en parte. Incorporando referencias complementarias en el seno de la materia novelesca, sus textos reúnen hechos averiguables, elementos verosímiles y datos creados; documentos oficiales se entrecruzan con testimonios orales y relatos remotos o clandestinos, para mejor enfocar a los héroes y sus dobles. Sobre héroes y tumbas y Abaddón el exterminador remiten a los destinos similares -pese a la distancia temporal- de dos figuras de un pasado digno de rememorar: el general Juan Galo Lavalle y el comandante Ernesto Che Guevara. Si ellos constituyen modelos esperanzadores más 
allá de sus fracasos al prolongarse continuamente en seres humildes, revelan también una cronología ineluctablemente violenta. Exponiendo lo que los documentos no logran expresar y que solo la ficción puede vislumbrar, adivinar, representar, la escritura se vuelve, más allá de las incertidumbres, una “memoria del bien" -invirtiendo de esta manera parte del título del libro de Tzvetan Todorov, Mémoire du mal; tentation du bienun espacio ajeno al olvido: el escenario mismo del héroe inmortal.

Abaddón el exterminador retoma el hilo de la narración dejado unos trece años antes por Sobre héroes y tumbas, estableciendo un lazo entre dos héroes históricos privilegiados en el seno de estas producciones, Lavalle y Guevara, quienes desempeñan en ellas un papel esencial pese a la brevedad de las referencias. En efecto, basta nombrarlos para identificarlos y para vincularlos con épocas claves de un pasado contemporáneo. Al recordar más particularmente el último período de sus itinerarios, Lavalle en Sobre héroes y tumbas, y Guevara en Abaddón el exterminador, parecen evidentes, transparentes, quedando asociados a reconocibles y famosos acontecimientos históricos. Ambos libros recalcan hechos verídicos que validan la verosimilitud de las acciones reproducidas.

Los dos participaron directamente, en siglos distintos, en violentas contiendas políticas en períodos decisivos de búsqueda identitaria que llevaron a brutales rupturas y a la perpetuación de la violencia en el espacio americano. La emancipación del territorio, la instauración de una legitimidad nacional así como la búsqueda de una alternativa política y de una nueva definición regional desembocaron a su vez en combates suplementarios, repetidos, anunciando otros más. De conflicto en conflicto, el continuo trasladarse de Lavalle y Guevara de un espacio abierto a otro los lleva de la legitimidad, de la declaración, a lo ilícito, a lo disimulado; de hecho, en la etapa final, la huida de la legión hacia la frontera boliviana y los desplazamientos de los revolucionarios en la selva se vuelven silenciosos, nocturnos.

El alférez Celedonio Olmos, como todos ellos, cabalga ceñudo y silencioso, recordando a su padre, el capitán Olmos, y a su hermano, muertos en Quebracho Herrado. (Sobre héroes 533)

Entre los últimos días de setiembre y los primeros de octubre, tratamos de mantenernos ocultos durante el día ... A las 2 de la madrugada paramos para descansar. Seguimos a las 4. Eramos 17 hombres, avanzando en la oscuridad y en el silencio angustioso para el cañadón de Yuro. (Abaddón 236-7)

Los dos sublevados heredan la ambivalencia de los héroes tradicionales que une en ellos permanencia y movimiento, legalidad y clandestinidad, autoridad y rechazo. Acaso de la fusión de estas tensiones contrarias se desprenda la rebelión misma, considerada por Ernesto Sábato como uno de los profundos e imperecederos rasgos de la identidad latinoamericana.

Entregándose a estrategias militares y acciones heroicas, Lavalle y el Che comparten una visión romántica de la reunión geográfica y política del subcontinente. Fieles a los primeros ideales de la emancipación, deciden luchar contra un poder tiránico -la federación argentina de Rosas en el siglo xıx; la dictadura boliviana en los años sesenta 
del siglo $\mathrm{xx}$ - a pesar de la escasez de sus tropas y de la pobreza de sus recursos, frente a un conflicto que es no solo intenso sino también implacable.

Ciento setenta y cinco hombres, rotosos y desesperados, perseguidos por las lanzas de Oribe, huyendo hacia el norte por la quebrada, siempre hacia el norte. (Sobre héroes 88)

Bueno, el ejército esperó hasta que ese miserable los llevara a la trampa, y cuando estaban vadeando el río los asesinaron por la espalda y allí murieron muchos y entre ellos Tania, una chica valiente, y solo quedaron 22 hombres. (Abaddón 227-8)

Ambos mueren ajusticiados y, si Bolivia permanece inalcanzable para el Lavalle vivo, se transforma en el sepulcro de Guevara después de haber sido el terreno de sus operaciones dirigidas contra el régimen militar local. En este país andino fue donde los dos permanecieron enterrados en sitios desconocidos volviéndose incorporales, aéreos (reencontrados, los restos mortales de Guevara han sido sepultados en una tumba oficial en Cuba hace pocos años).

Sus figuras se vuelven legendarias, y más particularmente la del comandante, que ha alcanzado una fama excepcional provocando fascinación por su aspecto caballeroso, su eterna juventud y sus actuaciones audaces. No obstante, ambos son "atípicos” por su destino mismo de vencidos, acompañados por un número cada vez más reducido de hombres a medida que se acerca el final trágico, la destrucción total. Por una parte, el papel de Lavalle es secundario en las guerras independentistas del Río de la Plata; además es minoritario frente a Rosas. Por otra, el Che se encuentra a sabiendas en una región inhóspita, sólo seguido por unos cuantos voluntarios; sin apoyo logístico, sabe que es desigual su combate contra un potente y adiestrado ejército.

Parecen haber fracasado; sin embargo, la verdad se encuentra en donde surge la resistencia. Es esta desesperada lucha la que atrae, al no aceptar la sumisión impuesta por la fuerza; seduce al proporcionar un fallecimiento glorioso, al continuar una revuelta sin triunfos. Su muerte se vuelve visible, admirable, ejemplar, memorable: es la conclusión, la consagración, la apoteosis de una intensa existencia que los lleva al punto más alto, más cercano del cielo.

Así que en medio de la destrucción de aquellas torres el alférez adolescente empezaba a entrever otra; refulgente indestructible. Una sola. Pero por ella valía la pena vivir y morir. (Sobre héroes 547)

No me atrevía a disparar. En ese momento vi al Che muy grande, enorme. Sus ojos brillaban intensamente. (Abaddón240-1)

Por su elevación, su luminosidad, la "torre” perpetua de Sobre héroes y tumbas es la imagen del absoluto tan buscado, sólo alcanzable con la muerte. También en el instante del fallecimiento que enfrenta con intenso coraje, Guevara, con cuerpo resplandeciente, enaltecido, inabarcable, accede a lo inolvidable, a la inmortalidad. De hecho, Abaddón el exterminador retoma a menudo la imagen de las “torres”: “También él había intentado ese ascenso. Cada vez que había sentido el dolor, porque esa torre era invulnerable... Encerrarse en la torre” (367). La novela termina con el discurso del personaje Bruno que 
se refiere a una "fortaleza”: "Y también alguna vez se dijo (pero quién, cuándo) que todo un día será pasado y olvidado y borrado: hasta los formidables muros y el gran foso que rodeaba a la inexpugnable fortaleza” (474).

A pesar de las dudas, la escritura permite recordar; la transcripción se transforma en ciudadela que protege y defiende la memoria, otorgando perennidad a la capacidad de rebelión y el acercamiento a la muerte de los dos héroes.

En ambas novelas, se enfoca el final de sus itinerarios durante los cuales se acumulan errores, fracasos, dudas, desaliento hasta el ineluctable término dado a sus vidas. Reúnen los rasgos característicos de la condición humana definida por Ernesto Sábato, volviéndose así los representantes arquetípicos del ser humano: “...el hombre queda definido por su dimensión metafísica, por ese conjunto de atributos que caracterizan a la condición humana: su ansia de absoluto, la voluntad de poder, el impulso a la rebelión, la angustia ante la soledad y la muerte" (El escritor... 141-42). ${ }^{1}$

Cumplen con un programa ontológico, reflejando los “problemas últimos” (132) del ser humano actual anunciando lo que Milan Kundera llama "el período de las paradojas terminales” (32). En efecto, la reconstitución de la trayectoria de la Legión dirigida por Lavalle en Sobre héroes y tumbas deja surgir un parangón entre la posindependencia y la situación argentina de los años sesenta en el siglo xx -la del período de escritura del libro. En efecto, se establece un claro paralelo entre la contienda que oponía unitarios y federales del siglo xIx, y la pugna entre peronistas y antiperonistas que desembocó, en 1955, en un golpe de Estado. Este se prolongó en un período de pronunciamientos anunciando la disolución posterior. “1955”, fecha clave, se encuentra en la frase inicial del primer capítulo del libro, señalando la continuidad lógica entre épocas distintas que concluyen en el final brutal de una ilusión.

Esta construcción paralela vuelve a repetirse en Abaddón el exterminador, lo que, además, apunta a una clara conexión con Sobre héroes y tumbas, pues el general Lavalle abre y cierra Abaddón el exterminador: surge con su reducida tropa en las primeras páginas, mediante alusiones a la corrección en vistas de la publicación de la novela anterior, Sobre héroes y tumbas; luego, aparece en las páginas finales recordando de manera paradójica el inicio de la epopeya mítica de los antepasados, cabalgando en el espacio abierto, el comienzo de la historia, que los lleva a volverse figuras ideales en busca de libertad, de fuerzas vitales: “...aquellas pampas que en otro tiempo habían sido recorridas por las caballadas del capitán Olmos, aquella tierra de donde salió, para nunca más volver, con sus hijos Celedonio y Panchito para seguir a Lavalle” (452).

Rodeado de unos pocos guerrilleros, el Che Guevara aparece como el heredero de los héroes de la emancipación. De hecho, la represión dirigida contra el grupo de rebeldes en la selva boliviana en 1967 resulta claramente relacionada, en el seno de la narración, a la que empezó a desatarse a principios de los años sesenta en Argentina, acarreando el sangriento y despiadado golpe militar de 1976. No es una casualidad el que la fecha “1973”, año del regreso de Perón, esté insertada en la misma primera página de Abaddón

\footnotetext{
1 Véase también Abaddón 242.
} 
el exterminador. Inicia la narración inscribiéndola en un período en el que comienza el apocalipsis anunciado por el título mismo y recalcado en una de las dos citas del peritexto. En efecto, la referencia a la última parte del Nuevo Testamento pone de realce la significación tautológica del nombre mismo del “Ángel del Abismo” remitiendo al precipicio en el que está cayéndose el universo entero y a una necesaria esperanza, a una salvación.

La segunda cita del escritor romántico ruso de la primera mitad del siglo XIX, Mijail Yúrievich Lermontov, propone una definición del misterio del ser con Un héroe de nuestro tiempo, título de su obra; sin duda, puede aplicarse al comandante Guevara, cuya evocación se encuentra en el centro mismo de Abaddón el exterminador, formando el eje esencial del texto por plantear de manera candente el sentido de la existencia humana. De hecho, trata de acercarse al enigma de la rebelión en un mundo que la aniquila, donde todo es absurdo.

Entrecruzar memoria e historia en el discurso narrativo permite rescatar a los héroes del olvido y otorgarles su verdadero estatuto de modelo. Para restituir mejor el itinerario agónico de la legión, en Sobre héroes y tumbas, se entremezclan los discursos de personajes de la ficción y una doble serie de cortísimos relatos imaginarios, en itálica, de los testigos directos, que se situan estratégicamente casi al abrir y al cerrar de la novela. Así, en el capitulo XII de la primera parte, el relato inaugural de Alejandra, clara personificación de Argentina, revela a Martín sus propios lazos familiares con dos de los tenientes de Lavalle. Esta enunciación, que une ficción e historia a través de los dos protagonistas, va complementándose con la rememoración del bisabuelo de Alejandra, Abuelo Pancho: él es el testigo indirecto de los hechos históricos al volverse el portavoz de los recuerdos de su propio padre, quien fue uno de los tenientes de Lavalle.

Abuelo Pancho comienza la evocación retrospectiva del antepasado con la repetición insistente de la misma cifra, la del número total de soldados, ciento setenta y cinco hombres, que acompañaron al general Lavalle en la retirada. Esta breve reiteración (en las páginas 91, 93 y 94) parece bastar para aludir a la caída de la legión e introducir la historia misma:

\footnotetext{
-Hornos los abandonó caramba. Dijo “me huiré al ejército de Paz” . Y los dejó con el comandante Ocampo también. Caramba. Y Lavalle los vio alejarse con sus hombres, hacia el este, en medio del polvo. Y mi padre dice que el general parecía lagrimear, mientras miraba los dos escuadrones que se alejaban. Ciento setenta y cinco hombres le quedaban. (94)
}

El Abuelo Pancho, el antepasado, amplifica la memoria ancestral poniéndola al servicio de lo inolvidable, del ausente digno de rememorar. Su actividad mnésica resulta interrumpida por nueve fragmentos en itálica que evocan los últimos momentos de Lavalle gracias a distintas voces. Resalta entre ellos el monólogo del espectro del general mismo quien interviene desde el más allá de la muerte haciendo un balance estoico y crítico a la vez de su propia experiencia:

He peleado en ciento y cinco combates por la libertad de este continente. He peleado en los campos de Chile al mando del general San Martin. Y en Perú a los órdenes del general 
Bolivar. Luché luego contra las fuerzas imperiales en el territorio brasileño. Y después de estos dos años de infortunio a lo largo y a lo ancho de nuestra pobre patria. Acaso he cometido grandes errores y el más grande de todos el fusilamiento de Dorrego. Pero ¿quién es dueño de la verdad? Nada sé ya fuera de que esta tierra cruel es mi tierra y que aquí tenía que combatir y morir. Mi cuerpo se está pudriendo sobre mi tordillo de pelea pero eso es todo lo que sé. (96)

Su estatuto de muerto-vivo le permite "encarnar" el recuerdo como huella de lo acontecido. De la misma manera, el monólogo del comandante Danel presenta el rápido paso de la gloria a la degradación de su jefe militar. El empleo del “yo” y del presente de la narración subraya lo inmediato del recuerdo, lo subjetivo de la introspección que remite a la sensación frente a una cronología hecha de numerosas guerras sucesivas:

Soy el comandante Alejandro Danel, hijo del mayor Danel, del ejército napoleónico. Todavía lo recuerdo cuando volvía con el Gran Ejército, en el jardín de las Tullerías o en los Campos Elíseos, a caballo...Aquella tarde de 1825 en que lo conocí y me pareció un águila imperial al frente de su regimiento de coraceros. Y entonces marché con él a la guerra del Brasil...Y nunca más me separé de él... Y ahora después de ochocientas leguas de tristeza, ahora marcho al lado de su cuerpo podrido, hacia la nada. (98)

Los soliloquios y los relatos entregados por un narrador omnisciente utilizan la actividad del recuerdo al transcribir la visión de los principales miembros de la Legión enfocados uno por uno: "Piensa Pedernera: veinticinco años de campañas, de combates, de victorias y derrotas. Pero en aquel tiempo, sí sabíamos por lo qué luchábamos. Luchábamos por la libertad del continente, por la Patria Grande. Pero ahora” (95).

Estos testimonios individuales restituyen la dimensión “vivida” de los acontecimientos, refiriéndose con melancolía a un pasado glorioso. Forman un conjunto "polifónico" que elabora un nuevo documento historiográfico al reconstituir, gracias a la escritura, la huida de la legión hacia Bolivia. La creación de declaraciones humanas, interiores, e incluso fantasmales, que entregan una versión parecida, dejan surgir una verdad tras la subjetividad de cada narración, tras la ficción.

En su discurso, el anónimo narrador extradiegético agrega un dato histórico descartado de la memoria de Abuelo Pancho, cumpliendo con lo que Paul Ricoeur ha llamado la “función correctiva de la verdad” (La mémoire 25):

Y una mujer. Pero el viejo no lo sabe o no lo quiere saber. He ahí todo lo que queda de la orgullosa Legión después de ochocientas leguas de retirada y de derrota, de dos años de desilusión y de muerte. Una columna de ciento setenta y cinco hombres miserables y taciturnos (y una mujer)... (94)

Desempeña el papel del historiador que retoma, en la cuarta y última parte, o sea en los capítulos terminales de Sobre héroes y tumbas, la segunda serie de relatos en itálica integrando trece secuencias más largas que completan los segmentos iniciales. En efecto, el narrador omnisciente reproduce, desde el presente del relato, la sucesión de los 
acontecimientos a partir de la traición de los comandantes Ocampo y Hornos, respetando esta vez la cronología. Hace nuevamente irrupción en las conciencias de Lavalle y de sus tenientes para entregar los datos desde sus propias sensaciones: "Ahora marchan hacia Salta por senderos desconocidos, senderos que sólo ese baqueano conoce. Son apenas seiscientos derrotados. Aunque él, Lavalle, cree todavía en algo...” (526); “Pedernera mira a Lavalle que marcha un poco adelante, con sus bombachas gauchas, su arremangada y rota camisa, un sombrero de paja. Está enfermo, flaco y caviloso: parece el harapiento fantasma de aquel Lavalle del Ejército de los Andes” (535).

La retrospección resulta más lógica al reproducir el encadenamiento de los sucesos. Sin embargo, aparece la regular repetición de los combates y de las derrotas, la periódica necesidad y fatalidad de los sacrificios: desde tiempos remotos, desde el origen, esta reiteración constituye, como lo sugiere el título bíblico de la obra, el sentido mismo de la existencia que fluye entre valor y muerte. No obstante, no impide el aspecto incomprensible, irracional de algunos hechos evocados por los actores mismos, como, por ejemplo, la ejecución de Manuel Dorrego mandada por Lavalle. La lucidez acerca del error probable surge de nuevo en la segunda intervención del fantasma de Lavalle cuyos pensamientos se dirigen a sus tenientes, desde su sepulcro, para acompañarles en el tramo final del éxodo hacia Bolivia: de hecho, remite a los temas bíblicos del vagar incesante de los primeros hombres rechazados del paraíso y de la huida inevitable del reducido pueblo elegido que no logrará hacer surgir una nueva humanidad. Lavalle se transforma así en un atormentado ser moderno que enfrenta lo enigmático sin poder encontrar una respuesta a sus interrogaciones.

Abaddón el exterminador utiliza la misma estrategia. Claramente diferenciado en el cuerpo narrativo gracias a una tipografía distinta, un conjunto de varios archivos aparece introducido y luego entrecortado por el soliloquio de Palito, guerrillero sobreviviente del último ataque militar contra la tropa del Che en la selva boliviana. Una parte de los documentos seleccionados son famosos. Las dos cartas del comandante Guevara y su diario ya no son privados sino elementos del patrimonio público que funcionan como pruebas de la determinación así como de la abnegación del guerrillero. La diversidad de los textos reproducidos indica la voluntad de mostrarlo todo, ya que los informes del ejército y de los periodistas son descriptivos, directos, fríos al relatar los hechos: "Nos desplegamos de modo de cercar a los guerrilleros y en seguida nos lanzamos al asalto. El primer rebelde que vimos era el que luego identificamos como Willy, seguido por el que después identificamos como el Che... (Informe del capitán Prado)” (238-9). En efecto, los catorce documentos historiográficos evocan los principales datos cronológicos durante las últimas semanas de existencia del grupo guerrillero, poniendo de relieve los días de la captura y el fusilamiento de su jefe, Guevara. Estos mismos momentos fueron los que Palito no presenció al lograr escapar y salvarse de la represión militar. Forman un verdadero via crucis que desemboca en el calvario, en una lenta agonía. Cada secuencia subraya el caracter crístico del sacrificio del Che y de sus compañeros, a pesar de la frialdad de los textos reproducidos. En cambio, el discurso de Palito dirigido a Marcelo, su narratario ficticio, da una visión desde el interior de la guerra de guerrillas; su versión, que evoca la acción rebelde en su cotidianidad, es el complemento de la serie de documentos 
de archivo. Como lo hacía Abuelo Pancho en Sobre héroes y tumbas, Palito es un testigo que utiliza su memoria destacando sus propios sentimientos, su afectividad: "Te dije que al poco tiempo le empezó a faltar su medicina para el asma, y sufría muchísimo. A veces se ocultaba en los momentos en que le daba peor. Pero luego volvía continuando la marcha” (231).

La revelación del pasado heroico se une al descubrimiento de la identidad misma de Palito: al confiar lo íntimo, lo secreto, saca de la clandestinidad a la vez a la figura prohibida del Che, el objeto de su enunciación, y a sí mismo, el guerrillero-enunciador. El entrecruzamiento entre historia y ficción, historia y memoria, permite utilizar un contrapunto entre su discurso-testimonio y los documentos oficiales que recalcan lo ineluctable del sacrificio. Asimimo intenta acercarse a la significación profunda de los hechos e impedir su olvido. En este sentido, no es la situación de Argentina la que importa en sí sino lo que permite revelar, en tanto teatro del surgimiento de desastres insuperables, del apocalipsis: indica el final de un mundo, del planeta entero, por repetir masacres, enfrentamientos fratricidas, la necesidad de la violencia es imperativa aunque absurda. Sin embargo, tanto Palito como Marcelo resisten a la "contaminación del mal” (Todorov 20); son combatientes humildes pero sublimes que luchan alcanzando, de manera fugaz, la pureza.

Las figuras heroicas sacadas de la historia son a la vez referenciales y míticas; son "humanas" y se han vuelto permanentes. Para acceder a la inmortalidad, tienen que entrar en la muerte. Se desplazan sin cesar asociando movimiento y velocidad para escapar a la finitud e inscribirse en la memoria de las acciones. La pugna contra lo inevitable se refleja en Sobre héroes y tumbas a través del reiterativo recuento de las leguas que separan la legión del territorio boliviano, el cual puede proporcionar una salvación y transformarse en la tierra prometida. Los testigos insisten en la distancia que queda por recorrer asociándola a la duración misma del éxodo; la velocidad del galope es primordial, mientras el cadáver del general se descompone y los enemigos se acercan. La celeridad se vuelve un leit motif, para transformar la derrota en victoria sobre el tiempo. De hecho, los relatos de cada soldado se construyen a partir de la descomposición del cadáver del general Lavalle que es necesario transportar para disimular, que es menester conservar para resistir al enemigo: "El coronel Pedernera ordena hacer alto y habla con sus compañeros: el cuerpo se está deshaciendo, el olor es espantoso. Se lo descarnará y se conservarán los huesos. Y también el corazón, dice alguien. Pero sobre todo la cabeza: nunca Oribe tendrá la cabeza, nunca podrá deshonrar al general” (101). El esqueleto, última forma humana reconocible, es el emblema del hombre muerto y a la vez del ser que permanece, deshecho de la carne vulnerable y corruptible.

La lucha contra la inminencia de la disolución se prolonga en el movimiento regresivo de las reminiscencias de la legión a propósito de sus hazañas pasadas: "Piensa Pedernera: veinticinco años de campañas, de combates, de victorias y derrotas. Pero en aquel tiempo sí sabíamos por lo que luchábamos. Luchábamos por la libertad del continente, por la Patria Grande. Pero ahora” (95). Estos últimos recuerdos contrastan con un presente de la narración degradado, caótico, acentuando de esta manera las interrogaciones, las incertidumbres de los miembros del batallón a propósito del sentido de una lucha ya perdida, de la validez de semejante sacrificio. 
De la misma manera, en Abaddón el exterminador, el paso de las horas y la rapidez necesaria de los repliegues determinan la sobrevivencia de los guerrilleros y ponen de relieve la proximidad cada vez más patente del término trágico. Pues el cansancio y las enfermedades se apoderan de los cuerpos, las maniobras se vuelven desesperadas: "El Moro sufría dolores insoportables y el Comandante estaba cada día peor, porque hacía rato que se le habían acabado los remedios para el asma...Ya sabíamos que el ejército conocía nustra posición” (234).

La degradación fisica anuncia la interrupción, la inmovilidad y la muerte que se acerca. Sin embargo, los fracasos desembocan a la vez en el fallecimiento y la perduración: al morir, los héroes y sus dobles se salvan descubriendo su verdad en la imperfección y en la pertenencia al género humano, en su fidelidad al absoluto. La muerte es el momento único, el instante puro en que se cumple el destino, el tiempo pasado que adquiere una forma luminosa.

Tanto Martín en Sobre héroes y tumbas como Marcelo en Abaddón el exterminador (los une el eco de sus nombres) salen de la confusión, del vértigo, al volverse los reflejos angelicales de los personajes históricos; son los nuevos héroes, sus continuas deambulaciones en la capital/infierno que refleja la anterior movilidad incesante de Lavalle y del Che en la naturaleza americana.

Martín se vuelve el alter ego de uno de los tenientes de Lavalle, Celedonio Olmos, por su juventud (tienen la misma edad) y su pureza. Este era uno de los antepasados de Alejandra/Argentina quien se hunde en el abismo, doble contrario del pasado celestial. Tras haber rozado la muerte, Martín escapa siguiendo una trayectoria paralela a la de la Legión hacia los espacios abiertos, límpidos de la Patagonia que unen lo patriótico y lo identitario dejando abierta una esperanza.

Surge con sus vacilaciones e interrogaciones en Abaddón el exterminador para elucidar el misterio de la identidad de Alejandra, sin lograrlo. El personaje, Marcelo, aparece como el doble tímido del Che al ser asmático como él. Conquista el territorio de la resistencia al sacrificarse a su turno: torturado en un calabozo disimulado, se transforma en una tenue luz en medio de las tinieblas gracias a la revelación de su verdad, de su humanidad en el momento de la destrucción, en la agonía, en la desaparición. A pesar de lo funesto, la búsqueda incesante no se termina con él; con su requiem, la sed de absoluto es irreprimible.

Tanto Sobre héroes y tumbas como Abaddón el exterminador incluyen un discurso estético a través de un personaje de escritor; de hecho, en el último libro, Sabato, el alterego del autor, y Bruno están muy presentes. Ambos intentan acercarse al misterio de la existencia, al enigma del valor y de la dignidad. También tratan de definir la chispa creadora que permite llevar a un instante de eternidad. A través de las figuras de los héroes, aluden también a la naturaleza paradójica del creador que se encuentra entre lo sublime de su visión poética, de su ideal, y la conciencia del límite de su existencia. Un paralelo se establece entre el escritor y el rebelde, uno y otro aceptando arriesgar su vida a cambio de traducir brevemente un absoluto, de entrar en la eternidad gracias al sacrificio, al arte. Si el héroe reúne en él historia y memoria, el autor también se define como una encrucijada 
entre dimensiones distintas: “...el escritor como entrecruzamiento de la realidad cotidiana y las fantasías, como límite entre la luz y las tinieblas” (El escritor 247).

Así la literatura se vuelve un arma contra la muerte, contra el olvido. Escribir es recordar los ideales heroicos, seguir otras aventuras, exponerse a otros riesgos. Sábato, héroe de la escritura y de la memoria, busca un sentido sacrificando su existencia a los signos, a las exigencias de la obra, dejándose devorar por ella para tratar de vencer la descomposición y el desorden. Resistir y escribir son actos heroicos; pues el autor se parece a un soldado épico al recomenzar diariamente su lucha narrativa, al perseguir continuamente coherencia y sentido. La búsqueda de la identidad literaria es parecida al combate empecinado por la conquista territorial, por la definición nacional. El libro se vuelve espacio soberano, el tiempo de la lectura aplazando el apocalipsis, el "Abaddón" que amenaza. Sumido en el caos de un universo incomprensible, no deja de ser clarividente entre catástrofes sucesivas que, no obstante, no logran destruir los caracteres irreductibles del hombre: subsisten la conciencia y la compasión incluso en los seres más despreciados, más humillados, durante los momentos más trágicos.

Definida en el título mismo de la obra Sobre héroes y tumbas, la historia aparece como un tiempo basado en la repetición de la rebelión y de la muerte omnipresente. Sin embargo, la reconstitución del pasado en el presente de la narración ya se sabe lección para el porvenir gracias a la mezcla de las huellas mnésicas individuales y de las colectivas, documentales. El libro como depositario del saber sobre los héroes recordados utiliza el esfuerzo de memoria para evitar que queden ocultados bajo el olvido; la página constituye el sepulcro que se les ha negado y, a la vez, los mantiene vivos, inmortales. Quizá la única salida a la fatalidad sea el absoluto del combate, del arte: permite superar la inevitable muerte, interrumpir una serie de fracasos, hacer perdurar a los héroes. Al depositar su memoria inmutable en el entramado textual, la narración intenta captar una débil claridad en medio de la oscuridad, suspendiendo, de este modo, el furor, y revirtiendo el tiempo desdichado en fugaz eternidad. La escritura da memoria a lo efímero de la admirable temeridad heroica, instante sublime, iluminación, en medio de la noche. Acaso la producción de Sábato encuentre así breves y secretos motivos de esperanza, a pesar de las dudas, de la absurda perpetuación de la violencia, del miedo a las tinieblas hacia las que parece dirigirse la humanidad.

BiBLIOGRAFIA

Calvino, Italo. La machine littérature. Paris: Seuil, 1984.

Compagnon, Antoine. Le démon de la théorie. Paris: Seuil, 1998.

Daros, Philippe. Italo Calvino. Paris: Hachette,1994.

Kristeva, Julia. Sèméiotikè. Recherches pour une sémanalyse. Paris: Seuil, 1969.

Kundera, Milan. L'art du roman.Paris: Gallimard, 1986.

Ricoeur, Paul. La mémoire, l'histoire, l’oubli. Paris: Seuil, 2000.

Temps et récit. T.III Paris: Seuil, 1985.

Sábato, Ernesto. El escritor y sus fantasmas. [1963] Barcelona: Seix Barral, 1987. Sobre héroes y tumbas. [1961] Barcelona: Seix Barral, 1987. 
Abaddón el exterminador. [1974] Barcelona: Planeta, 1985.

Todorov, Tzvetan. Mémoire du mal. Tentation du bien, enquête sur le siècle. Paris: R.Laffont, 2000. 